\begin{abstract}
Three experiments examined conceptual change from reading refutational texts, and how such learning interacted with prior knowledge organization. Prior to reading, three groups of learners were identified based on their prior knowledge of the targeted concept: two groups held misconceptions; one was generally accurate. Experiment 1 tested learning from a text that contrasted a misconception and the correct conception of the phenomenon of airflow against learning from a text that repeated the correct scientific description twice. Both reader groups learned from both types of texts about equally. Experiment 2 contrasted a more traditional refutational text to the "repetition" text. Learning was better with the refutational than the repetition text for both misconception groups on both measures. Experiment 3 demonstrated that learners who held largely accurate conceptions prior to reading texts that presented misconceptions preserved their largely accurate performance. Overall, the results suggest that the inclusion of an explicit refutation of the misconception is critical for instigating knowledge revision when readers possess inaccurate prior conceptions.
\end{abstract}




\section{The influences of text and reader characteristics on learning from refutations in}

\section{science texts}

Conceptual change research indicates that readers often rely on naïve, misconceptionbased prior knowledge when attempting to comprehend scientific texts (Alvermann, Smith, \& Readence, 1985; Dole, 2000; Guzzetti, 2000; Kendeou \& van den Broek, 2005). Prior knowledge can be characterized as misconception-based when the reader's conception differs from the currently accepted scientific conception ${ }^{1}$ (Driver, Squires, Rushworth, \& Wood-Robinson, 1994; McCloskey, 1983; Sarampungavan \& Wiers, 1997; Vosniadou \& Brewer, 1992). Many researchers have argued that misconceptions are quite ubiquitous and that they are impediments to the acquisition of more scientifically acceptable conceptions, especially when "coherent" or “strongly held" (Dole, 2000; Dole \& Sinatra, 1998; Hewson \& Hewson, 1984). In particular, some have argued that holding a coherent misconception may overwhelm recognition of its inconsistency with the scientific conception (Otero \& Kintsch, 1992; Posner, Strike, Hewson, \& Gertzog, 1982). This may be particularly the case when instruction does little to highlight the presence of misconceptions and promote their active revision (Chambliss \& Calfee, 1998; Champagne, Gunstone, \& Klopfer, 1983; Driver \& Easley, 1978; Hewson \& Hewson, 1984; Pace, Marshall, Horowitz, Lipson, \& Lucido, 1989; West \& Pines, 1985).

To address this conundrum, a general sequence of instructional practices has been developed for the purposes of remediating misconceptions (Alparslan, Tekkaya, \& Geban, 2003; Duit \& Treagust, 2003; Hewson \& Hewson, 1983; Posner, et al., 1982; Smith, Blakeslee, \& Anderson, 1993). First, researchers consider the kinds of misconceptions that learners most often display when learning in the domain of interest. Then, attempts are made to activate these 
misconceptions, with explicit "tags" of inaccuracy. This is followed by an introduction of the more appropriate, scientifically accepted conception.

One way in which this instructional approach to conceptual change has been implemented is through the use of refutational texts (Dole, 2000; Guzzetti, 2000; Guzzetti, Snyder, Glass, \& Gamas, 1993; Hynd, 2001; Hynd \& Guzzetti, 1998). Refutational texts comprise three key features, corresponding to the three elements of the instructional sequence listed above. A misconception believed to be commonly-held is described. Then the refutational statement states that the misconception is, in fact, inaccurate ("If you also think in this way, you are mistaken...”). Immediately afterwards, the scientifically accepted conception is presented as a contrast (Dole, 2000; Guzzetti, 2000; Hynd, 2003; Hynd \& Guzzetti, 1998; van den Broek \& Kendeou, 2008). In the typical experimental paradigm, conceptual change after reading a refutational text is compared to conceptual change after reading a "non-refutational" version of the correct content. That is, the non-refutational comparison texts only present the scientificallyaccepted conception with no mention of the misconception.

Research conducted using the typical paradigm has shown positive effects of refutational texts on retention of science information and inference-level or application performance compared to reading non-refutational texts across a range of science topics and age groups (Alvermann \& Hague, 1989; Ariasi \& Mason, 2011; Chambers \& Andre, 1997; Diakidoy, Kendeou, \& Ioannides, 2003; Diakidoy, Mouskounti, \& Ioannides, 2011; Guzzetti, Williams, Skeels, \& Wu, 1997; Hynd, Alvermann, \& Qian, 1997; Hynd, McWhorter, Phares \& Suttles, 1994; Mason \& Gava, 2007; Mason, Gava, \& Boldrin, 2008; Mikkilä-Erdmann, 2001). At the same time, other research studies have failed to find positive effects for refutational texts either on retention (Kendeou, Muis, \& Fulton, 2011; Kendeou \& van den Broek, 2007; Mason, et al., 
2008; Mikkilä-Erdmann, 2001) or learning of the scientific content (Alvermann \& Hague, 1989; Broughton, Sinatra, \& Reynolds, 2010; Hynd \& Guzzetti, 1998; Kendeou \& van den Broek, 2007; Kendeou, et al., 2011; Mikkilä-Erdmann, Penttinen, Anto, \& Olkinuora, 2008; Palmer, 2003). There are additional concerns that refutational texts might introduce misconceptions to readers who do not already hold them (Hynd, et al., 1997).

We see two major issues regarding the inconsistent results of reading refutational texts on conceptual change. The first involves assumptions about how refutational and non-refutational texts are processed and potential interactions with readers' prior knowledge. The second involves specific features of the refutational as well as the non-refutational texts used in previous studies.

\section{Processing Models for Refutational and Non-refutational Texts}

Given the differences between refutational and non-refutational texts, most theories of text processing, learning, and memory would predict differences in how readers would process each type of text and in the resulting mental representations of the information. In particular, generic activation-based text processing models (Kintsch, 1994; 1998; Linderholm, Virtue, Tzeng, \& van den Broek, 2004; Myers \& O’Brien, 1998) would predict that the misconception in a refutational text should activate the misconception in the prior knowledge of the reader. The sequential structure of the three statements in the refutational text implies that the misconception would be available in consciousness when the statement of its inaccuracy and the correct conception are processed on subsequent input cycles. In the non-refutational text, the misconception is never mentioned, nor indicated as incorrect. As such, there is a much lower likelihood that that a reader's misconception would become activated from prior knowledge alongside the correct concept. Kendeou and colleagues' co-activation hypothesis states that when the misconception and the correct conception are co-activated in working memory as a result of 
reading refutational texts, these conditions support readers' engagement in more strategic conceptual change processing in service of reconciling the discrepancies between the text and prior knowledge. In support of this hypothesis, Kendeou and colleagues demonstrated that readers allocate more time on target scientific sentences in refutation versus control versions of texts, and their think-aloud comments reveal more "conceptual change strategies" on the target scientific sentences (Kendeou \& van den Broek, 2007; Kendeou, et al., 2011; van den Broek \& Kendeou 2008). Ideally, discrepancy resolution attempts in response to refutational texts would result in conceptual change favoring the scientific conception.

Although the processing characterization outlined above designates knowledge activation as central for instigating conceptual change from texts, refutational text research has not systematically investigated the role of individual differences in the misconception(s) that readers bring to the processing of refutational or non-refutational texts. In fact, a critical review of the literature suggests that empirical investigations rarely restrict their recruitment criteria for participation to individuals who clearly endorse misconceptions prior to reading. This is particularly problematic for claims about a refutational text's effectiveness in promoting conceptual change from misconception-based to more accurate conceptions. A major issue for the present research is whether and how the refutational text effect is affected by the content and structure of a reader's prior knowledge related to the concept and misconceptions about it.

\section{Prior Knowledge of Misconceptions}

Two theoretical positions dominate the discourse regarding the knowledge organization of misconceptions in science. One position posits that misconceptions are coherently organized around implicit "theories" (Gopnick \& Wellman, 1994; Vosniadou \& Mason, 2011; Wellman \& Gelman, 1992). Support for this position comes from data indicating that learners are relatively 
consistent in their use of one misconception when generating predictions and causal explanations across a variety of contexts (Carey, 1985; 1991; 2000; Chi, 1992; 2005; Chi, Slotta, \& de Leeuw, 1994; Ioannides \& Vosniadou, 2002; McCloskey, 1983; Slotta \& Chi, 2006; Slotta, Chi, \& Joram, 1995; Vosniadou, 1994; Vosniadou \& Brewer, 1992; 1994; Watson, Prieto, \& Dillon, 1997). The other theoretical position holds that misconceptions emerge from prior knowledge about a topic that is incoherent, and fragmented in "pieces" (diSessa, 1988; 1993; diSessa, Gillespie, \& Esterly, 2004). That is, from a "pieces" perspective, prior knowledge consists of unstructured collections of many discrete elements that become activated based on their perceived relevance to the situation (diSessa, 1993; in press; Özdemir \& Clark, 2007). Support for a fragmentary position comes from data indicating that learners generate contradictory, inaccurate predictions and causal explanations across a set of problems that should invoke the same scientific conception (Clark, 2006; Cooke \& Breedin, 1994; diSessa, 1993; 1996; 2002; Galili \& Bar, 1997; Ranney, 1994; Tytler, 1994). Thus, “knowledge in pieces” proponents contend that inconsistent and unsystematic responding across problem contexts is evidence for knowledge structures that are fragmentary, and too weakly organized to be considered “coherent" or "theory-like" (Clark, 2006; diSessa, 1988; 1993; 2002; diSessa, et al., 2004; Hammer, 1996; Smith, diSessa, \& Roschelle, 1993).

Although both theoretical approaches to conceptual change assume that readers construct, modify and revise mental representations as new information is encountered, the theories differ in their views of the initial properties of prior knowledge, as discussed above, which in turn can be seen to affect the nature and scope of the revision process (Özdemir \& Clark, 2007). In particular, the coherence of knowledge structures at the initial knowledge state has implications for the activation of information from long-term memory during text processing (Ericsson \& 
Kintsch, 1995). In the case of holding a coherent naïve theory about a topic, a large, tightly connected network of propositions related to the reader's misconception will become activated during reading, whereas holding fragmentary knowledge would lead to relatively more isolated activation of propositions in long-term memory. The differences in patterns of activation among ideas in long-term memory could then affect the detection of conflict while reading, as well as the extent to which prior knowledge is modified to weaken initial misconceptions and to strengthen the coherence and stability of the correct conception.

For readers who hold fragmentary misconceptions, a set of discrete elements may become activated in long-term memory due to semantic overlap with the text input. We assume these isolated ideas might not accrue sufficient activation to remain in consciousness when subsequent sentences are read, including the disconfirmation sentence and the statement of the scientifically accurate conception. In response to the sentences conveying the scientifically accurate information, an altogether different set of knowledge elements may become activated. Accordingly, readers with fragmented misconceptions might be less likely to notice a discrepancy or experience cognitive conflict since misconceptions would not be co-present in consciousness with the correct conception. Thus, readers with fragmented prior knowledge may be less likely to revise their prior knowledge, less likely to attempt to reconcile different representations with each other, and less likely to generate a coherent and stable representation of the correct conception. A representation of the correct conception might be established, but it may become just one of many possible understandings that can be brought to bear in new contexts.

On the other hand, for readers with a coherent misconception, reading the refutational text would activate a connected network of propositions related to the misconception (Goldman, 
Varma, \& Coté, 1996; van den Broek, Young, Tzeng, \& Linderholm, 1999). Because this knowledge is represented in a network, the information should stay relatively active for a longer period of time, and therefore would be more likely to be active when the disconfirming statement and then the statement of the correct concept are read. According to van den Broek and Kendeou (2008), the co-activation of the misconception at the same time as the correct conception should support recognition of a discrepancy between the accurate input sentence and the entire misconception network. As such, readers with coherent misconceptions might be more likely to experience cognitive conflict, which some consider a critical impetus for conceptual change (Chan, Burtis, \& Bereiter, 1997; Chinn \& Brewer, 1998; Hewson \& Hewson, 1984; Posner, et al., 1982). Detecting conflict may prompt a revision or replacement process that could weaken the representation of incorrect conceptions in memory. Encountering an elaboration or explanation about the correct concept could also help to increase the coherence and stability of the representation of the accurate concept in memory. At the same time, enhancing the correct knowledge representation could help to weaken the misconception network. Thus, refutational texts might particularly encourage readers with coherent misconceptions to intentionally revise, reorganize or replace their misconceptions in favor of the correct scientific conception via explicit attempts to relate prior understandings to the novel conception.

The present research examined the role of differences among readers in the structure of prior knowledge about a target scientific principle (differences in air pressure causing air-flow) on post-reading recognition and recall memory tasks. Experiments 1 and 2 compared readers holding fragmentary versus coherent misconceptions and Experiment 3 examined readers whose understanding was largely correct.

\section{The Impact of Text Characteristics on the Refutational Text Effect}


A second reason that research is inconsistent regarding evidence for conceptual change from reading refutational texts may reside in variability in the structure and content of the refutational and comparison non-refutational text. The refutational text effect is based on comparing performance after reading the refutational text compared to performance after reading the non-refutational text. Accordingly, if refutational statements only imply that the misconception is inaccurate, it may not be a strong enough "confrontation" of the reader's belief to produce a significantly different result than reading a non-refutational version. For example, some refutational statements merely imply inaccuracy ("the scientific explanation is a bit more complex than this..."), whereas others explicitly state that the misconception is not accurate ("If you believe this, you are wrong."). Previous studies that used texts containing explicit refutational statements such as the latter tended to produce more robust learning advantages compared to their respective control texts (Ariasi \& Mason, 2011; Mason, et al. 2008; Vilppu, Mikkilä-Erdmann, \& Ahopelto, 2011) or to results from other studies in which the refutation of the misconception was less explicit (Alvermann \& Hague, 1989; Broughton, et al., 2010). In the present research, we examined whether the refutational statement was present or not and the impact on performance in relation to prior knowledge differences.

At the same time, characteristics of text that increase performance from the nonrefutational text could also result in failure to find a benefit of the refutational text, even though both texts produce conceptual change. For example, in some studies, additional information has been added to the non-refutational text to equate for length with the refutational text (Alvermann \& Hague, 1989; Broughton, et al., 2010; Kendeou \& van den Broek, 2007; Kendeou, et al, 2011; Palmer, 2003). Examples of "filler" information include additional everyday examples of the core principle or conceptual elaboration. As per the process model, this type of elaborative and 
explanatory information could increase the activation of the correct conception leading to a stronger memory trace for the correct conception. A stronger representation of the correct conception in the non-refutational text condition would thereby reduce the difference between the conceptual change observed in the refutational and non-refutational conditions. This may account for the failure to find effects of the refutational text in several previous studies.

In the present research, to equate the length of the two types of texts, we added direct paraphrases of the correct conception, thus repeating the same exact semantic information without further elaboration. Although repetition of the "same" idea could strengthen that idea (Amlund, Kardash, \& Kulhavy, 1986; Barnett \& Seefeldt, 1989), it would be expected to have a lesser impact than elaboration or explanation since it would only involve the single idea and not a network of ideas connected to the correct conception.

\section{The Present Research}

The present research explored the role of differences in prior knowledge about the target scientific principle as well as issues regarding the characteristics of the "refutational" and "nonrefutational" texts used in prior refutational text research. In Experiments 1 and 2 we investigated whether individuals who held relatively coherent misconceptions regarding reasons that air flows might experience greater learning from reading contrastive or refutational texts than readers who held fragmented misconceptions. In Experiment 3 we examined whether readers who did not hold the misconception addressed in the texts actually experienced performance decrements reading the contrast (used in Experiment 1) or refutational text (used in Experiment 2) relative to readers of the repetition texts used in those experiments.

A minimum of three weeks prior to participating in the actual experiments, the participants in each of the experiments completed an assessment of prior knowledge about 
causes of air flow in several everyday contexts. Performance profiles on that assessment were used to categorize participants as holding coherent misconceptions (i.e. response patterns that suggested consistent use of a theory-like misconception across several contexts), fragmented misconceptions (i.e., response patterns that suggested several misconceptions of similar “strength"), or mostly accurate understandings that air pressure differentials cause air flow. Details are provided below.

\section{EXPERIMENT 1}

Experiment 1 compared learning outcomes of individuals displaying coherent versus those displaying fragmented misconception profiles as a function of reading two different versions of the text. As indicated earlier, the co-activation hypothesis (Kendeou \& van den Broek, 2007; van den Broek \& Kendeou, 2008) as well as more passive activation-based text processing models predict that cotemporaneous presence-in-consciousness of the misconception and the correct conception are necessary for conceptual change. In Experiment 1 we tested whether the copresence of the misconception and the correct conception in the text was sufficient to induce conceptual change and whether sufficiency was related to coherent versus fragmentary misconceptions. Thus, the texts in Experiment 1 did not include the explicit refutation statement of the misconception that is typically included in refutational texts. Accordingly, we refer to this text as a "contrast" text since it does not fulfill all three characteristics of true refutational texts. Conceptual change in response to this "contrast" text was compared to a text that presented the scientific conception with a paraphrase restatement of it, minimizing elaboration effects of information added to equate length of the two texts. We refer to this text as the "accurate repetition" text since it repeated the correct conception twice. We expected greater impact of contrast texts on participants holding coherent as compared to fragmentary misconceptions due 
to the higher likelihood of coherent misconceptions as compared to isolated ones remaining active when the accurate conception is read.

\section{Method}

\section{Participants}

One-hundred and eighteen undergraduates (68\% female) at a large Midwestern university participated in the learning from text experimental session. All participants were fluent English speakers. Compensation for participation was course credit in an introductory psychology course at the university.

\section{Experimental design}

Experiment 1 used a 2 (text type: contrast, repetition) x 2 (misconception profile prior to reading: coherent, fragmented) between-participants design to explore the potential interaction between type of text and misconception profile in learning scientific content. Learning was tested using a re-administration of the multiple-choice recognition memory assessment used to determine prior knowledge and by responses to short essay questions about situations that were discussed in the texts.

\section{Materials}

Multiple-choice knowledge assessment. A 10-item multiple-choice assessment was developed to assess prior knowledge and learning after participants had read the text appropriate to their experimental condition.

All questions assessed the same underlying principle: air flow in relation to pressure differentials. There were two items per each of five situational contexts (why ears pop given changes in altitude, why air moves from a deflating tire, why air moves from a deflating balloon, 
why winds occur in weather systems, and why air moves into vacuums). Each item required recognition of the accurate response from among a set of 5 multiple-choice response options. The multiple-choice response options for each item expressed different causes of air movement. One response option was developed to reflect the scientifically accepted conception - pressure differentials cause air movement from areas of higher to lower air pressure until reaching a state of equilibrium (Basca \& Grotzer, 2001; Tytler, 1998). Additional response options reflected three misconceptions commonly displayed in a number of everyday scenarios in previous research (Basca \& Grotzer, 2001; Braasch \& Goldman, 2006; deBerg, 1995; Engel Clough \& Driver, 1985; Seré, 1982; Tytler, 1998). The misconception featured in the contrast and refutational texts, for example, stated that air pressure builds up to some threshold and causes air movement until there is no air or air pressure left in the object (hereafter referred to as the "all or none" air pressure misconception). Basca and Grotzer (2001), deBerg (1995), and Engel Clough and Driver (1985) have all demonstrated that students frequently rely on the "all or none" air pressure misconception when reasoning about air flow. Another misconception stated that the higher atmospheric pressure outside of the object exerts a downward force on the outside of the object, resulting in air movement out (the incorrect implication is that air moves from an area of lower to an area of higher air pressure). The third type of misconception stated that air does not appreciate confinement and naturally wants to move into empty spaces. An additional idiosyncratic response option for each item was developed to account for additional contextspecific misconceptions, and also to guard against potential response biases.

For each item, the response options were randomly ordered. Moreover, ordering of the sequence of items was based on two blocks, one per each set of five situational contexts. That is, the first block involved a randomized order of one item per each of the five situational contexts. 
The same approach was taken for the second block, with the constraint that the last item in block 1 could not involve the same situational context as the first item in block 2. Questions were presented in a different order for the two administrations.

Text Materials. "What causes air movement" was the topic of the focal text. The first two partitions of the table in Appendix A show the full versions of the contrast and repetition versions of the texts used in Experiment 1. Both texts were divided into three discrete pages. In both versions, the first page was identical and described definitional information on air pressure and its relationships with altitude.

The first paragraph on the second page was the focus of the experimental manipulation. In the contrast text, the first paragraph introduced the "all or none" air pressure misconception within the context of an everyday example of ears popping during increased elevation (signified in italics). As stated above, contrary to the scientific conception, the misconception is that air pressure builds up to some threshold and, when your ears pop, there is no air or air pressure left inside of your ear. The last sentence of the first paragraph states that the scientific explanation is a bit more complex than this.

To control for length, the first paragraph of the repetition text omitted the description of the misconception and instead presented paraphrases of the scientific conception that would later be presented in paragraph two (see the sentences in italics in the first partition of the table).

The presentation of the scientific conception in the second paragraph on page two was identical across the contrast and repetition text versions. That is, both explicitly conveyed the target scientific principle that pressure differentials cause air movement from areas of higher to lower air pressure and that, when air is not moving, it is because pressure systems are in a state of equilibrium. The third page was also identical across the text versions and presented the 
scientific conception to explain a new domain: reasons winds occur in weather systems. Word length (contrast: 885; repetition: 878) and readability (contrast: grade 8.0; repetition: 7.9 ) were comparable for the two texts.

Short Answer Essays. Short-answer essay prompts were constructed to assess knowledge of the target relationship between air pressure and air movement within two situational contexts that were discussed in the text (e.g., Based on what you know, explain why your ears pop when you ascend rapidly in an airplane). The two short essay prompts were printed on separate sheets of paper. Instructions stated that participants were to provide as much detail and be as complete as they could in their explanations.

Demographic Survey. Demographic measures were collected to examine whether there were systematic differences in the characteristics of participants in the various conditions. The demographic survey requested self-reports of age, gender, native language, status in school, grade point average, scores on achievement tests (ACT or SAT), perceived interest in the text and the topic area (using a 7-point Likert rating scale), status and major area of study in school, and the completed number and topics of prior science classes. Finally, participants completed a 20-item fill-in-the-blank test of general knowledge in earth and physical sciences, subject-matter domains that cover air pressure and air movement (e.g., What is the tendency for an object to stay at rest?).

\section{Procedure}

Participants were recruited from among those who were identified as having the fragmentary or the coherent misconception profile (See Coding below for inclusion criteria). Within each profile type, participants were randomly assigned to either the accurate repetition or the contrast text condition. Experimental sessions were conducted in large groups in a computer 
lab that contained IBM-compatible PCs. The texts were presented using E-Prime software (2000). Participants first read a "warm-up" text on an unrelated topic to acclimate them to reading from the computer screen and to using the space bar to advance through subsequent screens. Participants could only advance to immediately succeeding pages using links embedded at the bottom of each page, and they were not allowed to go back to previously read pages.

After the "warm up" text, the E-Prime software presented participants with instructions for the text about causes of air movement. They were instructed to read the text on causes of air movement to be able to answer both short essay and multiple-choice questions based on what they read. They were told they would not be able to reference the text while answering the questions. Participants were told prior to the experiment that they would have up to 20 minutes to read the texts. The software recorded reading times per page.

After participants finished reading, they were provided with the short answer essay writing task and a pencil to write their short essay responses. Instructions were to write each response directly on the prompt sheet and to provide complete responses to each question. Participants were allotted fifteen minutes to write the short answer essays and all finished in that time. After completing the essays, participants were provided with the multiple-choice knowledge assessment and were allotted ten minutes for its completion. Finally, participants completed the demographic survey in the allotted time of ten minutes.

\section{Coding}

Prior Knowledge Profiles. A minimum of three weeks prior to conducting any of the experiments, the 10-item multiple-choice prior knowledge assessment was distributed in a mass testing session to 1388 students and used to identify potential participants. The criteria for 
coherent misconception and fragmentary misconception profiles were set by first noting that chance correct performance was $20 \%$ (5 response options).

Coherent misconception profiles were attributed to those participants who selected the "all or none" air pressure distractor on at least 40\% (4 of 10) of the items, with no other type of response option (either distractor or correct option) selected on more than 3 items. Twelve percent of the sample met the criteria for the coherent misconception profile. Fragmented misconception profiles were attributed to those participants who selected among the four incorrect response options relatively equally, with no more than 3 correct answers. Seventeen percent of sample met this criterion. Only individuals who met one of these two misconception profile criteria were solicited for participation in Experiments 1 and 2.

Those eligible for participation in Experiment 3 provided evidence for a Partially correct profile in that they selected the correct response option on at least $50 \%$ of the items. More specifically, $96 \%$ in this profile group selected between 5 and 7 correct items; the remaining $4 \%$ selected 8 or 9 correct responses. In addition, selection of any one type of distractor was well below chance levels for the participants displaying the partially correct profiles prior to reading. Forty-eight percent of the sample met these criteria. Cronbach's $\alpha$ reliability scores for the multiple-choice measure were .57 (pre) and .59 (post). Although low for conventional reliabilities, low values can be expected where a degree of fragmentation, i.e. inconsistent responding across items, occurred on both pre and post-tests.

Core concepts included in Short Answer Essays. Each essay was scored using a set of seven scientifically-accepted concepts that were included in the accurate contrast and repetition texts. Taken together, these core concepts constitute a complete, accurate depiction of the focal 
relationship presented in the texts: a pressure gradient force (differences in air pressure) causes air movement. Appendix B provides definitions and examples of coded statements of accurate and inaccurate versions of the core concepts mentioned in the short answer essays. The first author in consultation with an earth scientist consultant identified the seven accurate concepts, as well as the ways that participants' inaccurately mentioned the concepts. A given sentence in a participant's essay could contain single, multiple or no concepts. For example, the sentence "When an airplane is "taking off," it gradually travels to higher altitudes ..." would not receive credit for any of the core concepts. However, had the sentence added “... where the air pressure is lower" it would have received credit for core concept 2 in Appendix B. Had the sentence added instead “... where the air pressure is lower compared to the higher air pressure inside of your ears" that sentence would have received credit for core concepts 2 and 3 . The first author went through all of the essays to generate a count of the number of correct and incorrect concepts included in each essay. An additional independent judge used the scoring rubric to score $20 \%$ of the essay responses. Cohen’s Kappa agreement was .92. Disagreements were resolved in discussion.

\section{Results}

\section{Misconceptions profiles}

Of the sample who participated in Experiment 1, individuals classified as having coherent misconception profiles more frequently selected the focal misconception response options $(M=$ 4.47, $S D=0.73$ ) compared to the individuals classified as having fragmented misconception profiles $(M=1.66, S D=0.47), t(116)=24.83, p<.001$. It was also important to establish that the two groups were similar with respect to selection of the scientifically accurate responses. Unfortunately, this was not the case in the sample for Experiment 1: individuals with coherent 
misconception profiles selected fewer accurate responses $(M=1.93, S D=1.16)$ compared to individuals with fragmented misconception profiles $(M=2.32, S D=0.80), t(116)=-2.13, p<$ .05. Because of this unexpected difference in prior knowledge, number of accurate responses on pre-test was entered as a repeated measure or a covariate in all analyses.

\section{Reading time}

Reading time (in seconds) on the manipulated page 2 was similar across text condition and misconception profile (fragmented-repetition: $M=125.84, S D=53.61$; fragmented-contrast: $M=107.34, S D=35.31$; coherent-repetition: $M=108.7, S D=26.45$; coherent-contrast: $M=$ $105.58, S D=27.28)$. That is, the main effect for text type $(F(1,114)=2.37, p=.13)$, the main effect for misconception profile prior to reading $(F(1,114)=1.81, p=.18)$, and the interaction $(F(1,114)=1.20, p=.28)$ were not significant

\section{Learning: Recognition memory}

A 2 (text type: contrast, repetition) x 2 (misconception profile prior to reading: coherent, fragmented) x 2 [test time: pre, post] repeated measures ANOVA on the performance on the

multiple choice test produced a main effect from pre to post, $F(1,114)=209.75, p<.001, \eta_{\mathrm{p}}{ }^{2}=$ .65 , and no other statistically significant effects, $F \mathrm{~s}(1,114)<2.03, n s$. The means are presented in Table 1. Overall, the analysis indicates that, regardless of text type or misconception profile, everyone selected around two and a half more items correctly after reading (pre: $M=2.12, S D=$ 1.00; post: $M=4.62, S D=1.79)$.

Insert Table 1 about here 
An additional 2 (text type: contrast, repetition) x 2 (misconception profile prior to reading: coherent, fragmented) x 2 [test time: pre, post] mixed ANOVA using the mean number of response selections indicating the "all or none" air pressure misconception showed a significant main effect from pre to post $\left(F(1,114)=96.23, p<.001, \eta_{\mathrm{p}}{ }^{2}=.46\right)$ and a main effect for misconception profile group $\left(F(1,114)=144.75, p<.001, \eta_{\mathrm{p}}{ }^{2}=.56\right)$. These main effects were qualified by a significant interaction between misconception profile and test time, $F$ (1, 114) $=125.33, p<.001, \eta_{\mathrm{p}}{ }^{2}=.52$. The simple effects demonstrate that learners with coherent misconception profiles significantly decreased their selection bias towards responses indicating the focal misconception from pretest $(M=4.48, S D=0.74)$ to post-test $(M=2.04, S D=1.08), F$ $(1,114)=224.86, p<.001, \eta_{\mathrm{p}}^{2}=.66$. Learners with fragmented misconception profiles did not reduce their selection of response options indicating the focal misconception from pre $(M=1.66$, $S D=0.48)$ to post-test $(M=1.82, S D=1.24), F(1,114)=1.23, n s$. This effect is not surprising given those with coherent misconception profiles simply had greater opportunities to decrease their selection of the all or none air pressure responses compared to those with fragmented misconception profiles. What is important to note is that there were no effects related to text type, $F \mathrm{~s}(1,114)<1, n s$. The response option targeted by the contrast text did not decrease in frequency relative to the accurate repetition text.

\section{Learning: Short-Answer Generation}

A 2 (text type: contrast, repetition) x 2 (misconception profile prior to reading: coherent, fragmented) Analysis of Covariance (ANCOVA) was conducted using proportion of accurate core concepts included in the short-answer essay responses as the dependent measure and number of scientifically accurate responses on the multiple choice pre-test as a covariate. As shown in Table 2, this analysis produced a main effect for misconception profile, $F(1,112)=$ 
9.53, $p<.01, \eta_{\mathrm{p}}{ }^{2}=.08$. After controlling for pretest performance, readers with coherent misconception profiles wrote essays that included a greater proportion of accurate core concepts $\left(M_{A}=0.79, S D=0.28\right)$ compared to readers with fragmented misconception profiles $\left(M_{A}=0.63\right.$, $S D=0.28)$. The main effect for text type $\left(F(1,112)=2.80, p<.10, \eta_{\mathrm{p}}{ }^{2}=.03\right)$ and the interaction $(F(1,112)<1, n s)$ were not significant.

\section{Tests for Differences in Demographic and General Science Knowledge}

Using the self-reported demographic information and performance on the general science knowledge assessment, exploratory analyses were conducted to confirm that there were not differences across conditions despite random assignment. A series of $2 \times 2$ between-participants ANOVAs were conducted using self-reported age, years in college, ACT performance, number of high school science courses completed, number of college science courses completed, interest ratings on the text and the topic, and the total correct on the general science knowledge assessment as the dependent variables. Additionally, dichotomous variables such as type of major (science vs. non-science), gender and first language were submitted to binary logistic regressions. For all analyses, text type and misconception profile were used as the independent variables. Based on the large number of statistical tests, a more stringent alpha level was adopted $(p<.01)$. There were no reliable main effects or interactions resulting from the analyses. It was noteworthy that those who had the coherent misconception profile prior to reading were no more or less knowledgeable about general concepts within earth and physical science domains (i.e. domains in which the relationship between air pressure and air movement is present) compared to those who had the fragmented misconception profile. Nor was scientific background (in terms of amount of training in the sciences or whether their major area of study involved a science) related to misconception profile. Thus, these analyses indicate that the differential learning 
effects for those with coherent versus fragmented misconception profiles are not indicative of systematic differences in other characteristics of these individuals.

\section{Discussion}

In Experiment 1, a contrastive text that contained both the misconception and the correct conception but lacked the third element of refutational texts - the explicit refutational statement - did not significantly improve readers' understanding above and beyond a text that repeated the scientific description twice. Analysis of the multiple-choice knowledge assessment data indicated that all readers generally increased their selection of scientifically accurate response options after reading, regardless of text type. And, there was a corresponding decrease in the choice of focal misconception distractors, particularly among the coherent profile readers, but this was equally likely regardless of text version. The results from the short-answer essay responses additionally indicated that a coherent misconception prior to reading had a positive effect on retrieval of information associated with correct conceptual understanding of air flow and pressure, but this was again unrelated to text version. Overall, the data from Experiment 1 indicate that simply presenting a misconception and then an accurate conception is insufficient to produce learning beyond that resulting from repetition of the correct conception.

\section{EXPERIMENT 2}

In Experiment 2, we inserted into the contrast text the explicit refutation statement that is a key feature of typical refutational texts. We again compared learning performance after reading on recognition and short answer generation tasks for learners with either coherent or fragmentary misconception profiles. We modified the accurate repetition text from Experiment 1 to highlight the scientific accuracy of the explanation described in that text. We did this so that any differences between the two texts could be attributed to the presence of the misconception and its 
refutation rather than to the explicit statement of accuracy of the scientifically correct conception. Thus, Experiment 2 compared a refutational text to a highlighted accurate repetition text.

These changes to the texts would be expected to strengthen the representation of the correct conception in memory for both text types. However, the refutational text should result in weakening of the all-or-none misconception, and possibly the whole network for the coherent misconception readers, more than the highlighted accurate repetition text.

\section{Method}

\section{Participants}

One-hundred and five undergraduates (68\% female) at a large Midwestern university participated in the learning from text experimental session. All participants were fluent English speakers. Compensation for participation was course credit in an introductory psychology course at the university. Experiment 2 incorporated the same criteria for participant solicitation as Experiment 1.

\section{Experimental design}

Experiment 2 used a 2 (text type: refutation, highlighted repetition) x 2 (misconception profile prior to reading: coherent, fragmented) between-participants design to explore the potential interaction between text type and misconception profile. As in Experiment 1, learning was tested using changes in pre-post performance on the multiple choice knowledge assessment as well as the proportion of accurate core concepts included in the short essay responses.

\section{Materials}

The same assessments were used as in Experiment 1. The second two partitions of the table in Appendix A show the full text versions in Experiment 2. As in Experiment 1, the two 
versions of the text were subdivided into three discrete pages. Only the first paragraphs on page two were modified. For the refutation text, an explicit refutation statement (let's explore people's commonsense, yet inaccurate beliefs) was inserted directly before the presentation of the misconception. The transition presented an additional signal of the accuracy of the scientific conception and a more direct statement that the two conceptions conflict (This belief, however, contradicts the scientifically accepted explanation. In contrast, scientific experiments have shown...).

The first paragraph on page two for the highlighted repetition text was also modified to more explicitly mark the accuracy of the scientific conception and the rhetorical structure of the text. An explicit marker (The general scientifically-accepted explanation is that...) was inserted directly before the first presentation of the scientific conception. The transition again signaled the accuracy of the scientific conception (This provides a nice overview of the scientifically accepted explanation), with an additional statement that the two paragraphs are paraphrases of one another (To put it another way, scientific experiments have shown...). Word length for the refutational and highlighted repetition versions of the text were identical (904 words). Readability (refutational: grade 8.2; highlighted repetition: 8.4) was comparable for the two texts.

\section{Procedure}

The procedure was identical to Experiment 1.

\section{Scoring of short essay responses}

The scoring was identical to Experiment 1. One rater scored all essays for correct and incorrect concepts. A second rater independently scored a random $20 \%$ of the essays. Cohen's Kappa reliability index between raters was .89. Disagreements were resolved in discussion.

\section{Results}




\section{Misconception profiles}

Individuals classified as having coherent misconception profiles more frequently selected this response $(M=4.47, S D=0.85)$ compared to those with fragmented misconception profiles $(M=1.75, S D=0.48), t(103)=20.23, p<.001$. In addition, individuals with coherent misconception profiles selected a similar number of correct responses $(M=1.93, S D=1.16)$ compared to those with fragmented misconception profiles $(M=2.32, S D=0.80), t(116)=$ $1.17, n s$. Although no differences in accurate prior knowledge were seen in this experiment, to provide consistency across experiments, pretest scores were again included in all analyses either as repeated measures or covariates.

\section{Reading time}

Reading time (in seconds) on the manipulated page 2 statistically differed across text type $_{2}, F(1,99)=7.64, p<.01, \eta_{\mathrm{p}}{ }^{2}=.07$. Highlighted repetition text readers spent a longer time on page $2(M=128.02, S D=42.24)$ compared to refutational text readers $(M=106.97, S D=$ 36.92). The misconception profile main effect and the interaction were not significant, $F \mathrm{~s}<1$.

\section{Learning: Recognition memory}

Table 1 displays the mean number of scientifically accurate response selections on the multiple- choice pre and post-tests as a function of learning condition. A 2 (text type: refutation, highlighted repetition) $\times 2$ (misconception profile prior to reading: coherent, fragmented) $\mathrm{2}$ [test time: pre, post] repeated measures ANOVA using number of scientifically accurate responses as the dependent measure demonstrated a main effect for test time, $F(1,101)=$ $163.69, p<.001, \eta_{\mathrm{p}}{ }^{2}=.62$ and a marginal main effect for text type, $F(1,101)=3.55, p=.06$, $\eta_{\mathrm{p}}{ }^{2}=.03$. However, these main effects were qualified by a significant interaction between text type and test time, $F(1,101)=4.41, p<.05, \eta_{\mathrm{p}}{ }^{2}=.04$. The data indicate that the refutational 
text readers displayed significant gains from pre $(M=2.13, S D=0.95)$ to post-test $(M=4.92, S D$ $=2.05), F(1,101)=114.74, p<.001, \eta_{\mathrm{p}}{ }^{2}=.53$. Highlighted repetition text readers showed the same general pattern (pre: $M=2.10, S D=1.08$; post: $M=4.10, S D=1.65), F(1,101)=55.43, p$ $<.001, \eta_{\mathrm{p}}{ }^{2}=.35$. However, those reading the refutational texts gained more correct responses $(M$ $=2.80, S D=1.99)$ than those reading the highlighted repetition texts $(M=2.00, S D=1.81), F$ $(1,101)=4.57, p<.05, \square \square \eta_{\mathrm{p}}{ }^{2}=.04$. There were no additional effects that were statistically significant, $F \mathrm{~s}(1,101)<1, n s$.

An additional 2 (text type: refutational, highlighted repetition) x 2 (misconception profile prior to reading: coherent, fragmented) $x 2$ [test time: pre, post] mixed ANOVA using number of response selections of the all-or-none air pressure misconception showed a significant main effect for test time $\left(F(1,101)=80.80, p<.001, \eta_{\mathrm{p}}{ }^{2}=.44\right)$ and a significant main effect for misconception profile $\left(F(1,101)=115.93, p<.001, \eta_{\mathrm{p}}{ }^{2}=.53\right)$. These main effects were qualified by a significant interaction between misconception profile and test time $(F(1,101)=$ 86.02, $\left.p<.001, \eta_{\mathrm{p}}{ }^{2}=.52\right)$. As in Experiment 1, this significant interaction demonstrates that individuals displaying the coherent misconception profile prior to reading significantly decreased their selection of the targeted all-or-none misconception from pre $(M=4.47, S D=0.73)$ to posttest $(M=2.07, S D=1.04), F(1,101)=175.88, p<.001, \eta_{\mathrm{p}}{ }^{2}=.64$. However, those who displayed the fragmented misconception profile prior to reading did not reduce their selection of responses indicating the targeted misconception from pre $(M=1.66, S D=0.47)$ to post $(M=$ $1.81, S D=1.22), F(1,101)<1, n s$. There was a trend reflected in the interaction of text type and test time, although it was not reliable statistically $\left(F(1,101)=2.79, p<.1, \eta_{\mathrm{p}}{ }^{2}=.03\right)$. This trend suggests that the refutational text (pre $M=3.22, S D=1.60$; post-test $M=1.74, S D=1.15$ ) was associated with a somewhat greater reduction in selection of the all-or-none distractor option 
than the highlighted repetition text (pre $M=3.02, S D=1.46$; post-test $M=2.06, S D=1.24$ ), $F$ $(1,101)=62.58, p<.001 \eta_{\mathrm{p}}^{2}=.38$, and $F(1,101)=24.86, p<.001, \eta_{\mathrm{p}}{ }^{2}=.20$, respectively.

The results of Experiment 2 indicate that the refutational text version produced significantly greater shifts toward correct multiple-choice responses than did the highlighted repetition text. This was true for both misconception profile groups. Thus, the results suggest that refutations more effectively produced conceptual change compared to texts that repeated the correct scientific principle.

\section{Learning: Short Answer Generation}

A 2 (text type: refutational, highlighted repetition) x 2 (misconception profile prior to reading: coherent, fragmented) ANCOVA was conducted using proportion of accurate core concepts included in the short-answer essay responses as the dependent measure and number of scientifically accurate responses on the pre-test as a covariate. As shown in Table 2, this analysis produced a main effect for misconception profile, $F(1,100)=6.17, p<.05, \eta_{\mathrm{p}}{ }^{2}=.06$. After controlling for pretest performance, readers with coherent misconception profiles wrote shortanswer essays containing a greater proportion of accurate core concepts $\left(M_{A}=0.78, S D=0.26\right)$ compared to readers with fragmented misconception profiles $\left(M_{A}=0.65, S D=0.26\right)$. Moreover, there was also a main effect for text type, $F(1,100)=6.28, p<.05, \eta_{\mathrm{p}}{ }^{2}=.06$. After controlling for pretest performance, readers of refutational texts displayed a greater proportion of accurate core concepts in their post-reading essays $\left(M_{A}=0.78, S D=0.27\right)$ compared to readers of texts that highlighted and repeated the accurate conception $\left(M_{A}=0.65, S D=0.26\right)$. The interaction between text type and misconception profile, however, was not significant, $F(1,100)<1, n s$. Tests for Differences in Demographic and General Science Knowledge Measures 
As in Experiment 1, the self-reported demographic information and performance on the general science knowledge assessment were submitted to a series of $2 \times 2$ between-participants ANOVAs (in the case of the continuous dependent measures) or binary logistic regressions (in the case of the dichotomous dependent measures). There were no reliable main effects or interactions resulting from the analyses. As in Experiment 1, these analyses confirmed that there were not differences between conditions that partially or completely accounted for the learning effects.

\section{Discussion}

Experiment 2 demonstrated that acquisition of the scientifically accurate air flow principle was more likely when both a contrast and an explicit refutation statement were present as compared to repetition of the correct conception, even when it was highlighted as the correct conception. Thus, it appears that the simultaneous presence of the misconception, the correct conception, and an explicit refutation of the misconception, produced greater conceptual change than simply emphasizing the correct conception by repeating it. This conclusion is reinforced by the trend for greater decreases in the all-or-none misconception distractor option following reading of the refutational as compared to the highlighted repetition text. The same reduction was not present in Experiment 1. Refutational text versions also led to better generation of short answer responses than did the highlighted repetition text. Again, the contrast text in experiment 1 did not produce this learning benefit either. Finally, overall, coherent misconception profile readers generally included more concepts in post-reading essays than fragmented profile readers, an effect that was present in both experiments.

\section{EXPERIMENT 3}


The purpose of Experiment 3 was to determine if reading a text that contained a misconception would interfere with the correct conception in readers who did not show evidence of holding the misconception prior to reading. A concern has been raised that presenting refutational texts to readers who do not hold the misconception discussed in the text could induce the misconception (Hynd, et al., 1997). If this is the case, then an expository text that only presents the scientifically accurate conception (like the accurate repetition versions used in the first two experiments) may afford a better learning opportunity than a text that presents the misconception. An alternate possibility is that the juxtaposition of the misconception and correct conception might generally strengthen students' accurate conceptions because the juxtaposition reflects "contrasting cases," an instructional strategy that has been shown to be highly effective (Schwartz \& Bransford, 1998).

In Experiment 3, we examined the impact of all four text versions from Experiments 1 and 2 on learners who did not show evidence of holding either coherent or fragmentary misconceptions based on performance on the prior knowledge assessment. Those solicited to participate in Experiment 3 performed at higher accuracy levels than those with misconceptions on the pre-test and did not meet the criteria for either coherent or fragmentary misconception profiles. Experiment 3 therefore tested whether exposure to texts that state a commonly held misconception might negatively impact learners who do not hold that misconception prior to reading it.

\section{Method}

\section{Participants}

One-hundred and ten undergraduates (55\% female) at a large Midwestern university participated in the learning from text experimental session. Participants were recruited from the 
same mass testing pool of 1388 students from which participants in Experiment 1 and 2 were drawn, except that eligibility for Experiment 3 was having a Partially correct profile (See Coding for the criteria). As in Experiments 1 and 2, all participants were fluent English speakers. Compensation for participation was course credit in an introductory psychology course at the university.

\section{Design}

Experiment 3 used a 4-level between-participants design in which each group received a different version of the text: contrast, repetition, refutation, highlighted repetition. All participants showed evidence of the partially accurate profile. As in Experiments 1 and 2, learning was tested using changes in pre-post performance on the multiple choice knowledge assessment as well as the proportion of accurate core concepts included in the short essay responses.

\section{Materials}

The same assessments and texts were used as in previous experiments.

\section{Procedure}

The procedure was identical to Experiments 1 and 2.

\section{Results}

\section{Pretest performance}

Average pretest scores for the four groups were similar (contrast: $M=5.31, S D=1.20$; repetition: $M=5.09, S D=1.10$; refutation: $M=5.52, S D=1.16$; highlighted repetition: $M=$ $5.23, S D=1.11)$. To provide consistency across experiments, pretest scores were again included in all analyses either as repeated measures or covariates.

\section{Reading time}


Reading times for page 2 , the focal pages exhibiting the text manipulations, were similar across the four text conditions (contrast: $M=107.25, S D=27.32$; repetition: $M=104.86, S D=$ 32.08; refutation: $M=100.36, S D=27.93$; highlighted repetition: $M=117.84, S D=41.13), F$ $(3,106)=1.22, n s$.

\section{Learning: Recognition Memory}

A 4 (text type: contrast, repetition, refutation, highlighted repetition) x 2 [pre, post] repeated measures ANOVA using multiple choice test performance as the dependent measure demonstrated a main effect for test time, $F(1,106)=41.56, p<.001, \square \eta_{\mathrm{p}}{ }^{2}=.28$. The text type main effect $(F(3,106)<1.19)$ and the interaction $(F(1,106)<1)$, however, did not approach statistical significance. Overall, the analysis indicates that, even though these students selected the correct response options with some regularity prior to reading, they were able to gain, on average, 1.2 more items correct on the post-test (pre: $M=5.29, S D=1.16$; post: $M=6.51, S D=$ 2.03).

\section{Learning: Short Answer Generation}

ANCOVA using text type as the 4-level independent variable, proportion of accurate core concepts included in the short-answer essay responses as the dependent variable, and pre-test scores as a covariate failed to produce a significant text type effect, $F(3,105)<1.02, n s$. Overall, the results indicate that, regardless of text type, readers included very high proportions of accurate concepts in their short-answer essays (contrast: $M_{\mathrm{A}}=0.82, S D=0.25$; repetition: $M_{\mathrm{A}}$ $=0.88, S D=0.19$; refutation: $M_{\mathrm{A}}=0.80, S D=0.27$; highlighted repetition: $M_{\mathrm{A}}=0.83, S D=$ 0.26).

\section{Discussion}


Experiment 3 suggests that, for learners who already have a partially accurate understanding within the domain, there were similar learning outcomes regardless of the type of text that was read. That is, reading any text presenting the scientifically accurate conception, regardless of whether it also presented it in contrast with a misconception, and whether or not the accuracy of the conceptions were specifically marked, resulted in significant learning gains. Moreover, the overwhelming majority of concepts included in reader-generated essays were accurate. The findings are consistent with a characterization that learners with enough correct knowledge did not need explicit markers of the accuracy of the correct conception to strengthen it. Instead, it appears to be the case that any presentation of the scientific conception served to strengthen readers' existing understandings into a more coherent and stable scientific conception. There was no evidence suggesting that reading a refutational text induced misconceptions.

\section{GENERAL DISCUSSION}

Three experiments tested whether different features of texts and prior knowledge organization impacted learning from scientific texts including those presenting refutations to a common misconception. Experiments 1 and 2 tested whether co-occurrence in the same text of the misconception statement and a statement of the scientifically accurate conception is sufficient to account for learning from refutational texts (Experiment 1), or whether learning requires the co-occurrence plus an explicit statement flagging the correct conception as accurate (Experiment 2). Both experiments also tested the possibility that the degree of misconception coherence in a reader's prior knowledge base - as indicated by their consistency in selecting misconceptionbased responses on an assessment administered prior to reading - moderated learning from refutations in scientific texts. Experiment 3 examined whether readers whose prior knowledge assessments showed little evidence of holding misconceptions actually experienced worse 
performance after reading texts that contained the misconception relative to similar readers who read texts that repeated the correct conception and did not mention the misconception. Two indices of learning that were included were meant to reflect the quality of and changes in readers' understandings. The first index of learning was a multiple-choice recognition memory test on which conceptual change was indicated by pre- to post-test increases in selecting the scientifically accurate responses and decreases in selecting the "all or none" misconception. Also, because the multiple-choice test required application to new topics, readers were required to reason and not merely superficially accept a directly stated fact. The second index was the number of correct concepts included in student-generated responses to short-answer questions. Generating an essay response from memory should also be affected by the quality of a reader's underlying situation model. The clearest evidence for coherent and accurate representations would be when both of these learning measures converge and show improvement.

Several main findings from these experiments have implications for the design of instructional texts. First, the results of Experiment 1 indicated that the co-occurrence of the misconception and the scientific conception in the same text (contrast condition) did not produce conceptual change to any greater degree than a text that presented the accurate conception twice. Second, the results of Experiment 2 indicated that a more traditional refutational text - one that included the misconception and the accurate conception and explicitly "tagged" them as such produced greater conceptual change than a text that presented the accurate conception twice and mentioned its accuracy. Third, the results of Experiment 3 demonstrated that refutational texts did not impart misconceptions to students who did not already hold them.

The different conceptual change effects for Experiments 1 and 2 have implications for theories of refutational text comprehension. First, the data are consistent with the assumption that 
the cotemporaneous presence-in-consciousness of the misconception and the correct conception is important for inducing conceptual change from scientific texts (Kendeou \& van den Broek, McCrudden, 2012; 2007; van den Broek \& Kendeou, 2008). However, the present research indicates that merely providing the misconception and accurate conception within the same text without explicit indication of which is accurate appears to be insufficient to produce conceptual change from reading, regardless of the organization of pre-reading misconceptions. The explicit refutational statement was necessary to produce conceptual change favoring the accurate conception for both groups of readers. There are a number of possible explanations for the importance of the explicit refutational statement. First, refutatational statements may make it more likely that readers "tag" misconception-based prior knowledge as incorrect, which may make it more likely that readers abandon their prior understanding in favor of the scientific conception that immediately follows that offers a plausible, and fruitful alternative (see the Conceptual Change Model of Posner, et al., 1982). At the same time, it might be the case that explicit refutational statements increase the likelihood that readers will experience cognitive conflict (Chan, Burtis, \& Bereiter, 1997; Hewson \& Hewson, 1984) and engage in more active resolution processes focused on resolving the discrepancies between inaccurate and accurate conceptions (Ariasi \& Mason, 2011; Chi, 2000; 2008; McCrudden, 2012). Future research employing trace methodologies - such as tracking eye movements during reading, collecting verbal protocols during reading, or some combination thereof - could help to determine the ways that the different refutational text features - especially the explicit refutational statement - might stimulate these conceptual change processes.

Although one needs to be cautious when making comparisons across experiments, the difference in learning patterns between Experiments 1 and 2 suggests that the previously 
obtained mixed results associated with refutations in text may be accounted for by the explicitness of the refutational statements used. Prior studies incorporating "refutational" texts that only imply inaccuracy (Alvermann \& Hague, 1989; Broughton, et al., 2010; Palmer, 2003) tended to report no memory or learning benefits from refutation compared to control conditions. On the other hand, refutational texts that clearly confronted readers' misconceptions using more explicit refutation statements ("If you also think in this way, you are mistaken") tended to result in significantly better learning outcomes than was seen with their respective control texts (Chambers \& Andre, 1997; Mason, et al., 2008; Vilppu, et al., 2011). Thus, what the current work adds to understanding the previous effects of refutations on science learning is that the explicitness of the refutational statement matters. Future research could directly manipulate the presence versus absence of the refutational statement within the same experiment to support this argument.

Previous research on refutation effects has also varied the kinds of texts used in the control conditions. In the current work, we chose to equate for length by adding paraphrased sentences of the scientific explanation that was to follow in subsequent text. We were concerned that text length equation strategies used in previous research (providing additional examples, introducing new terminology or conceptual elaboration) may have strengthened the representation for the correct alternative rather than being neutral. Previous text processing research has demonstrated that paraphrasing does not appear to be related to the construction of deeper understandings of the textual information (Coté, Goldman, \& Saul, 1998; Goldman, Braasch, Wiley, Graesser, \& Brodowinska, 2012). Thus, we equated for length by repeating the same semantic information from the scientific explanation sentences. 
At the same time, however, one could argue that even the repetition of information related to the correct scientific conception raised control readers' performance up to that of the refutation conditions (an argument that seems especially relevant for Experiment 1). Indeed, others have demonstrated that repeated readings of expository texts increase recall compared to single readings (Amlund, et al., 1986; Barnett \& Seefeldt, 1989). Although it is unlikely that repetition-related memory benefits for the textbase would improve performance on our learning measures since readers needed to construct inferences to be able to accurately respond, it is still possible that the repetition of the scientific conception benefited the control groups. Thus, future work would also be well informed by the use of a variety of comparison conditions.

The present experiments also have implications for theories of conceptual change, and provide insight into the potential role that misconception coherence may play in learning from scientific texts in general. Rather than pitting the two predominant theoretical approaches to conceptual change (Implicit Theory vs. Knowledge in Pieces) against each other, in this set of studies we used the two alternative approaches as a way of examining individual differences in the kinds of misconceptions that were held. Indeed, we were able to identify some students who held more coherent misconceptions about the topic and some who seemed to have more fragmented prior knowledge about the topic, which suggests that both approaches may be correct for some students at least some of the time. Furthermore, these differences that were identified between students in the nature of their misconceptions were seen to affect understanding of the accurate conception.

Several researchers have previously posited that "coherent" or "strongly held" misconceptions within a scientific domain may be detrimental to the acquisition of the accurate conception (Dole, 2000; Dole \& Sinatra, 1998; Hewson \& Hewson, 1984). However, the current 
work provides evidence that coherent pre-reading misconceptions were not detrimental to learning compared to fragmentary pre-reading misconceptions. In fact, there was evidence in both Experiments 1 and 2 that readers who held coherent misconceptions prior to reading generated more accurate core concepts after reading, regardless of the texts they read. The shortanswer generation results are inconsistent with a characterization that a stronger, more coherent misconception might "overwhelm" recognition of the inconsistency with the scientific conception (Dole, 2000; Otero \& Kintsch, 1992; Posner, et al., 1982). Instead, the data support the notion that the more coherent misconception network underwent a decrease in strength as a function of reading. Readers with coherent misconceptions may have experienced cognitive conflict when reading any text presenting the scientific conception. The statements presenting the correct concepts, however, appeared to be insufficient for the fragmentary misconception group to edit and restructure their knowledge elements into more appropriate, scientific understandings. As a consequence, they generated correct concepts in a more limited fashion than did the coherent misconception group.

Although the demographic analyses in both experiments showed no differences between students who were classified into the different misconception profiles on several reader characteristics including general knowledge of scientific concepts in earth and phy sical sciences, breadth of science courses taken, and whether or not the reader was a science major, other variables that we did not assess in the current work may relate to misconception coherence. It is unknown whether the coherent and fragmented misconception profiles relate differently to other individual differences measures such as readers' epistemic beliefs in the domain of interest (e.g., do students who believe that knowledge is certain also display coherent misconception prior to reading?). Other work has already begun to explore how this characteristic may predict 
conceptual change in science (Franco, et al., 2012; Mason, et al., 2008). Future research could explore relationships between misconception coherence and additional reader characteristics, examining their potential contributions to learning from scientific texts including those with refutations.

In conclusion, this set of experiments is particularly informative to understanding of refutational text comprehension because it is the first to separate the independent contributions of the contrast between the misconception and scientifically accepted conception from the contribution of the explicit refutation statement. The current findings suggest that it is the marriage of the key refutational text features that stimulates conceptual change, especially for learners who endorse misconceptions prior to reading. It is important to note that none of the findings suggest any detriments to learning in presenting common misconceptions in scientific texts, just differential benefits depending on the text features included and the content of prior knowledge. If we assume, as others have (e.g., Perkins \& Simmons, 1988), that misconceptions are the norm in science learning contexts, the present findings highlight the importance of providing additional opportunities to recognize when and how prior knowledge differs from the novel scientific conception being described. Additional research should more fully specify the complex ways that tasks, text features, prior knowledge and other reader characteristics may interact to affect conceptual change in a variety of different scientific domains. Extensions in this vein seem necessary, particularly when considering scientific texts and textbooks rarely address readers' misconceptions in overt ways (Chambliss, 2002), and readers may be unlikely to notice contrasts and discrepancies on their own (Epstein, Glenberg, \& Bradley, 1984; Glenberg, Wilkinson, \& Epstein, 1982; Noordman, Vonk, \& Kempff, 1992; Otero \& Kintsch, 1992; Wiley \& Myers, 2003). The most important charge for future work will be to develop conditions that 
Refutational texts 39

support learners of varied backgrounds in overcoming the misconceptions they bring to learning contexts. 


\section{References}

Alparslan, C., Tekkaya, C., \& Geban, Ö. (2003). Using the conceptual change instruction to improve learning. Journal of Biological Education, 37, 133-137.

Alvermann, D. E., \& Hague, S. A. (1989). Comprehension of counterintuitive science text: Effects of prior knowledge and text structure. Journal of Educational Research, 82, 197202.

Alvermann, D. E., Smith, L. C., \& Readence, J. E. (1985). Prior knowledge activation and the comprehension of compatible and incompatible text. Reading Research Quarterly, 20, 420-436.

Amlund, J. T., Kardash, C. A. M., \& Kulhavy, R. W. (1986). Repetitive reading and recall of expository text. Reading Research Quarterly, 21, 49-58.

Ariasi, N. \& Mason, L. (2011). Uncovering the effect of text structure in learning from a science text: An eye-tracking study. Instructional Science, 39, 581-601.

Barnett, J. E. \& Seefeldt, R. W. (1989). Read something once, why read it again?: Repetitive reading and recall. Journal of Literacy Research, 21, 351-360.

Basca, B. B., \& Grotzer, T. A. (2001, April). Focusing on the nature of causality in a unit on pressure: How does it affect student understanding? Presented at the annual meeting for the American Educational Research Association. Seattle, WA.

Braasch, J. L. G. \& Goldman, S. R., (2006). College Students' Understanding of Pressurized Air Movement: Do Isomorphic Questions Elicit Isomorphic Answers? Proceedings of the $7^{\text {th }}$ International Conference for the Learning Sciences: Bloomington, IN.

Broughton, S. H., Sinatra, G. M., \& Reynolds, R. E. (2010). The nature of the refutation effect: An investigation of attention allocation. Journal of Educational Research, 103, 407-423. 
Carey, S. (2000). Science education as conceptual change. Journal of Applied Developmental Psychology, 21, 13-19.

Carey, S. (1991). Knowledge acquisition: Knowledge enrichment or conceptual change? In S. Carey, \& R. Gelman (Eds.) The Epigenesis of the Mind: Essays on Biology and Cognition (pp. 257-292). Mahwah, NJ: Lawrence Erlbaum Associates.

Carey, S. (1985). Conceptual change in childhood. Cambridge, MA: MIT Press.

Chambers, S. K. \& Andre, T. (1997). Gender, prior knowledge, interest and experience in electricity and conceptual change text manipulations in learning about direct current. Journal of Research in Science Teaching, 34, 107-123.

Chambliss, M. J. (2002). The characteristics of well-designed science textbooks. In Otero, J., Leon, J. A., Graesser, A. C. (Eds.), The psychology of science text comprehension (pp. 51-72). Mahwah, NJ: Lawrence Erlbaum Associates.

Chambliss, M. J. \& Calfee, R. C. (1998). Textbooks for learning: Nurturing children's minds. Oxford, UK: Blackwell Publishers.

Champagne, A. B., Gunstone, R. F., \& Klopfer, L. E. (1983). Naïve knowledge and science learning. Research in Science and Technological Education, 1, 173-183.

Chan, C., Burtis, J., \& Bereiter, C. (1997). Knowledge building as a mediator of conflict in conceptual change. Cognition and Instruction, 15, 1-40.

Chi, M. T. H. (2008). Three types of conceptual change: Belief revision, mental model transformation, and categorical shift. In S. Vosniadou (Ed.), International handbook of research on conceptual change (pp. 61-82). New York, NY: Routledge.

Leon, J. A., Graesser, A. C. (Eds.), The psychology of science text comprehension (pp. 51-72). Mahwah, NJ: Lawrence Erlbaum Associates. 
Chi, M. T. H. (2005). Commonsense conceptions of emergent processes: Why some misconceptions are robust. Journal of Learning Sciences, 14, 161-199.

Chi, M. T. H. (2000). Self-explaining expository texts: The dual processes of generating inferences and repairing mental models. In Glaser, R. (Ed.), Advances in Instructional Psychology (pp. 161-238). Mahwah, NJ: Lawrence Erlbaum Associates.

Chi, M. T. H. (1992). Conceptual change within and across ontological categories: Implications for learning and discovery in science. In R. N. Gliere (Ed.), Cognitive models of science: Minnesota studies in philosophy of science (vol. 15, pp. 129-187). Minneapolis: University of Minnesota Press.

Chi, M. T. H., Slotta, J. D., \& de Leeuw, N. (1994). From things to processes: A theory of conceptual change for learning science concepts. Learning and Instruction, 4, 27-43.

Chinn, C. A. \& Brewer, W. F. (1998). An empirical test of a taxonomy of responses to anomalous data in science. Journal of Research in Science Teaching, 35(6), 623654.

Clark, D. B. (2006). Longitudinal conceptual change in students' understanding of thermal equilibrium: An examination of the process of conceptual restructuring. Cognition and Instruction, 24, 467-563.

Cooke, N. J. \& Breedin, S. D. (1994). Constructing naïve theories of motion on the fly. Memory \& Cognition, 22, 474-493.

Coté, N., Goldman, S. R., \& Saul, E. U. (1998). Students making sense of informational text: Relations between processing and representation. Discourse Processes, 25, 1-53. deBerg, K.C. (1995). Student understanding of the volume, mass, and pressure of air within a sealed syringe in different states of compression. Journal of Research in Science Teaching, 
$32,871-884$.

Diakidoy, I. N., Kendeou, P., \& Ioannides, C. (2003). Reading about energy: The effects of text structure in science learning and conceptual change. Contemporary Educational Psychology, 28, 335-356.

Diakidoy, I. N., Mouskounti, T., \& Ioannides, C. (2011). Comprehension and learning from refutation and expository texts. Reading Research Quarterly, 46, 22-38.

diSessa, A. A. (in press). A bird's-eye view of the "pieces" vs. "coherence" controversy (From the pieces side of the fence). In S. Vosniadou (Ed.), International handbook of research on conceptual change (2nd Ed.). New York: Routledge.

diSessa, A. A. (2002). Why conceptual ecology is a good idea. In M. Limon \& L. Mason (Eds.), Reconsidering conceptual change: Issues of theory and practice (pp. 28-60).

diSessa, A. A. (1996). What do "just plain folk" know about physics? In D. R. Olson \& N. Torrence (Eds.), The handbook of education and human development: New models of teaching, learning, and schooling (pp. 709-730).

diSessa, A. A. (1993). Towards an epistemology of physics. Cognition and Instruction, 10, 105225.

diSessa, A. A. (1988). Knowledge in pieces. In G. Foreman \& P. Pufall (Eds.), Constructivism in the computer age (pp. 49-70). Mahwah, NJ: Lawrence Erlbaum Associates.

diSessa, A. A., Gillespie, N. M., \& Esterly, J. B. (2004). Coherence versus fragmentation in the development of the concept of force. Cognitive Science, 28, 843-900.

Dole, J. A. (2000). Readers, texts and conceptual change learning. Reading \& Writing Quarterly, 16, 99-118. 
Dole, J. A., \& Sinatra, G. M. (1998). Reconceptualizing change in cognitive construction of knowledge. Educational Psychologist, 33, 109-128.

Driver, R. \& Easley, J. (1978). Pupils and paradigms: A review of the literature related to concept development in adolescent science students. Studies in Science Education, 5, 6184.

Driver, R., Squires, A., Rushworth, P., \& Wood-Robinson, V. (1994). Making sense of secondary science. New York: Routledge.

Duit, R. \& Treagust, D. F. (2003). Conceptual change: A powerful framework for improving science teaching and learning. International Journal of Science Education, 25, 671-688.

Engel Clough, E. \& Driver, R. (1985). What do children understand about pressure in fluids. Research in Science \& Technological Education. 3(2), 133-144.

Epstein, W., Glenberg, A. M., \& Bradley, M. M. (1984). Co-activation and comprehension: Contribution of text variables to the illusion of knowing. Memory \& Cognition, 12, 355360.

Ericsson, K. A. \& Kintsch, W. (1995) Long-term working memory. Psychological Review, 102, 211-245.

Franco, G. M., Muis, K. R. Kendeou' P., Ranellucci, J., Sampasivam, L., \& Wang, X. (2012). Examining the influences of epistemic beliefs and knowledge representations on cognitive processing and conceptual change when learning physics. Learning and Instruction, 22, 62-77.

Galili, I. \& Bar, V. (1997). Children's operational knowledge about weight. International Journal of Science Education, 19(3), 317-340.

Glenberg, A. M., Wilkinson, A. C., \& Epstein, W. (1982). The illusion of knowing. Failure in the 
self-assessment of comprehension. Memory \& Cognition, 10, 597-602.

Goldman, S. R., Braasch, J. L. G., Wiley, J., Graesser, A. C., \& Brodowinska. K. M. (2012). Comprehending and learning from Internet sources: Processing patterns of better and poorer learners. Reading Research Quarterly, 47, 356-381.

Goldman, S. R., Varma, S., Coté, N. (1996). Extending capacity-constrained construction integration: Toward "smarter" and flexible models of text comprehension. In B. K. Britton \& A. C. Graesser (Eds.), Models of text comprehension (pp. 73-113). Hillsdale, NJ: Lawrence Erlbaum Associates.

Gopnick, A., \& Wellman, H. M. (1994). The theory theory. In L. A. Hirschfeld \& S. A. Gelman (Eds.), Mapping the mind: Domain specificity in cognition and culture (pp. 257-293). New York: NY: Cambridge University Press.

Guzzetti, B. J. (2000). Learning counter-intuitive science concepts: What have we learned from over a decade of research. Reading \& Writing Quarterly, 16, 89-98.

Guzzetti, B. J., Snyder, T. E., Glass, G. V., \& Gamas, W. S. (1993). Promoting conceptual change in science: A comparative meta-analysis of instructional interventions from reading education and science education. Reading Research Quarterly, 28, 116-159.

Guzzetti, B. J., Williams, W. O., Skeels, S. A., \& Wu, S. M. (1997). Influence of text structure on learning counterintuitive physics concepts. Journal of Research in Science Teaching, $34,701-719$.

Hammer, D. (1996). Misconceptions or P-prims: How may alternative perspectives of cognitive structure influence instructional perceptions and intentions? The Journal of Learning Sciences, 5, 97-127.

Hewson, M. G. \& Hewson, P. W. (1983). Effect of instruction using students' prior knowledge 
and conceptual change strategies on science learning. Journal of Research in Science Teaching, 20, 731-743.

Hewson, P. W. \& Hewson, M. G. (1984). The role of conceptual conflict in conceptual change and the design of science instruction. Instructional Science, 13, 1-13.

Hynd, C. (2001). Refutational texts and the change process. International Journal of Educational Research, 35, 699-714.

Hynd, C. (2003). Conceptual change in response to persuasive messages. In G. M. Sinatra \& P. R. Pintrich (Eds.), Intentional conceptual change (pp. 291-315). Mahwah, NJ: Erlbaum. Hynd, C., Alvermann, D., \& Qian, G. (1997). Preservice elementary teachers' conceptual change about projectile motion: Refutational text, demonstration, affective factors, and relevance. Science Education, 81, 1-27.

Hynd, C. \& Guzzetti, B. J. (1998). When knowledge contradicts intuition: Conceptual change. In Hynd, C. (Ed.), Learning from text across conceptual domains (pp. 139-163). Mahwah, NJ: Lawrence Erlbaum Associates.

Hynd, C., McWhorter, J. Y., Phares, V. L., \& Suttles, C. W. (1994). The role of instructional variables in conceptual change in high school physics topics. Journal of Research in Science Teaching, 31, 933-946.

Ioannides, C. \& Vosniadou, S. (2002). The changing meaning of force. Cognitive Science Quarterly, 2, 5-61.

Kendeou, P., Muis, K. R., \& Fulton, S. (2011). Reader and text factors in reading comprehension processes. Journal of Research in Reading, 34, 365-383.

Kendeou, P., \& van den Broek, P. (2007). Interactions between prior knowledge and text structure during the comprehension of scientific texts. Memory \& Cognition, 35, 1567- 
1577.

Kendeou, P., \& van den Broek, P. (2005). The Effects of Readers' Misconceptions on Comprehension of Scientific Text. Journal of Educational Psychology, 97, 235-245.

Kintsch, W. (1998). Comprehension: A paradigm for cognition. New York: Cambridge University Press.

Kintsch, W. (1994). Text comprehension, memory, and learning. American Psychologist, 294303.

Linderholm, T., Virtue, S., Tzeng, Y., \& van den Broek, P. (2004). Fluctuations in the availability of information during reading: Capturing cognitive processes using the landscape model. Discourse Processes, 37, 165-186.

Mason, L. \& Gava, M. (2007). Effects of epistemological beliefs and learning text structure on conceptual change. In S. Vosniadou, A. Baltas, \& X. Vamvakoussi (Eds.), Reframing the conceptual change approach in learning and instruction (pp. 165-196). Elsevier.

Mason, L., Gava, M., \& Boldrin, A. (2008). On warm conceptual change: The interplay of text, epistemological beliefs, and topic interest. Journal of Educational Psychology, 100, 291309.

McCloskey, M. (1983). Naïve theories of motion. In D. Gentner \& A. L. Stevens (Eds.), Mental Models (pp. 299-324). Mahwah, NJ: Lawrence Erlbaum Associates.

McCrudden, M. T. (2012). Readers' use of online discrepancy resolution strategies. Discourse Processes, 49, 107-136.

Mikklä-Erdmann, M. (2001). Improving conceptual change concerning photosynthesis through text design. Learning and Instruction, 11, 241-257.

Mikklä-Erdmann, M., Penttinen, M., Anto, E., \& Olkinuora, E. (2008). Constructing mental 
models during learning from scientific text. In D. Ifenthaler, P. Pirnay-Dummer, \& J. M. Spector (Eds.), Understanding Models for Learning and Instruction: Essays in honor of Norbert M Seel (pp. 63-79). Springer.

Myers, J. L., \& O’Brien, E. J. (1998). Accessing the discourse representation during reading. Discourse Processes, 26(2\&3), 131-157.

Noordman, L. G., Vonk, W., \& Kempff, H. J. (1992). Causal inferences during the reading of expository texts. Journal of Memory and Language, 31(5), 573-590.

Otero, J., \& Kintsch, W. (1992). Failures to detect contradictions in text: What readers believe versus what they read. Psychological Science, 3, 229-235.

Özdemir, G. \& Clark, D. B. (2007). An overview of conceptual change theories. Eurasia Journal of Mathematics, Science, and Technology, 3, 351-361.

Pace, A. J., Marshall, N., Horowitz, R., Lipson, M. Y., \& Lucido, P. (1989). When prior knowledge doesn't facilitate text comprehension: An examination of the issues. In S. McCormick, \& J. Zutell (Eds.), Cognitive and social perspectives for literacy research and instructions. Thirty-eighth Yearbook of the National Reading Conference (pp. 213-224). Chicago, IL: The National Reading Conference, Inc.

Palmer, D. H. (2003). Investigating the relationship between refutational texts and conceptual change. Science Education, 87, 663-684.

Perkins, D. N., \& Simmons, R. (1988). An integrative model of misconceptions. Review of Educational Research, 58, 303-326.

Posner, G. J., Strike, K. A., Hewson, P. W., \& Gertzog, W. A. (1982). Accommodation of a scientific conception: Toward a theory of conceptual change. Science Education, 66, 211227. 
Ranney, M. (1994). Relative consistency and subjects' "theories” in domains such as naïve physics: Common research difficulties illustrated by Cooke and Breedin. Memory \& Cognition, 22, 494-502.

Samarapungavan, A. \& Wiers, R. (1997). Children's thoughts on the origin of species: A study of explanatory coherence. Cognitive Science, 21, 147-177.

Schwartz, D. L. \& Bransford, J. D. (1998). A time for telling. Cognition and Instruction, $16,475-522$.

Seré, M. (1982). A study of some frameworks used by pupils aged 11-13 years in the interpretation of air pressure. European Journal of Science Education. 4(3), 299309.

Slotta, J. D. \& Chi, M. T. H. (2006). The impact of ontology training on conceptual change: Helping students understand the challenging topics in science. Cognition and Instruction, $24,261-289$.

Slotta, J. D., Chi, M. T. H., \& Joram, E. (1995). Assessing students' misclassifications of physics concepts: An ontological basis for conceptual change. Cognition and Instruction, 13, 373-400.

Smith, E. L., Blakeslee, T. D., \& Anderson, C. W. (1993). Teaching strategies associated with conceptual change learning in science. Journal of Research in Science Teaching, 30, 111126.

Smith, J. P., diSessa, A. A., \& Roschelle, J. (1993). Misconceptions reconceived: A constructivist analysis of knowledge in transition. Journal of the Learning Sciences, 3 , $115-163$.

Strike, K.A., \& Posner, G.J. (1982). Conceptual change and science teaching. European Journal 
of Science Education, 4, 231-240.

Tytler, R. (1998). Children's conceptions of air pressure: exploring the nature of conceptual change. International Journal of Science Education, 20, 929-958.

Tytler, R. (1994). Consistency in children's use of science conceptions: Problems with the notion of "conceptual change." Research in Science Education, 24, 338-347.

van den Broek, P. \& Kendeou, P. (2008). Cognitive processes in comprehension of science texts: The role of co-activation in confronting misconceptions. Applied Cognitive Psychology, 22, 335-351.

van den Broek, P., Young, M., Tzeng, Y., Linderholm, T. (1999). The landscape model of reading: Inferences and the on-line construction of a memory representation. In H. van Oostendorp \& S. R. Goldman (Eds.), The construction of mental representations during reading (pp. 71-98). Mahwah, NJ: Lawrence Erlbaum Associates.

Vilppu, H., Mikkilä-Erdmann, M., \& Ahopelto, I. (2011). The role of regulation and processing strategies in understanding science texts among university students. Scandinavian Journal of Educational Research, 55, 1-17.

Vosniadou, S. (1994). Capturing and modeling the process of conceptual change. Learning and Instruction, 4, 45-69.

Vosniadou, S. \& Brewer, W. F. (1994). Mental models of the day/night cycle. Cognitive Science, 18, 123-183.

Vosniadou, S. Brewer, W. F. (1992). Mental models of the earth: A study of conceptual change in childhood. Cognitive Psychology, 24, 535-585.

Vosniadou, S., \& Mason, L. (2011). Conceptual change induced by instruction: A complex interplay of multiple factors. In K. Harris, C.B. McCormick, G.M. Sinatra \& J. Sweller 
(Eds.), Educational psychology: Contributions to education (pp. 221-246). Washington, DC: American Psychological Association.

Watson, J. R., Prieto, T., \& Dillon, J. S. (1997). Consistency of students' explanations about combustion. Science Education, 81, 425-443.

Wellman, H. M. \& Gelman, S. A. (1992). Cognitive development: Foundational theories of core domains. Annual Review of Psychology, 43, 337-375.

West, L. H. T., \& Pines, A. L. (1985). Cognitive structure and conceptual change. Orlando, Fl: Academic.

Wiley, J. \& Myers, J. L. (2003). Availability and accessibility of information and causal inferences from scientific text. Discourse Processes, 36(2), 109-129. 


\section{Footnotes}

${ }_{1}$ We incorporate the term "misconception" - as it is frequently used in the research literature on conceptual change - to describe prior knowledge that is of a different structure than the scientifically accepted conception. We recognize definitional similarities with other descriptors such as "alternative conception," "alternative framework," "intuitive or naïve conception," and "preconception," to name but a few.

2 Two outliers were removed because their reading times exceeded 3 standard deviations above the mean. 


\section{Appendix A}

\section{Experimental text materials}

\section{PAGE 1}

Air pressure is the force of air pressing down on the Earth's surface. As air is all around us, there is air pressure all around us too. The amount of air pressure at any given point depends upon the density of air molecules above that measuring point. Although air molecules are tiny and invisible, they still have weight and take up space. Sometimes more air molecules than usual are compressed in a particular region. When this happens, that area is said to be "under high pressure." Accordingly, high pressure areas have more air molecules, or atmospheric mass, above their location. On the other hand, areas of low pressure have less atmospheric mass above their location. Comparatively, they are not under as much compression.

But how does air pressure affect us? Particularly, what happens to us if air pressure changes suddenly? Interestingly, our bodies continually adapt to the pressure around us. Living in Chicago, the air pressure at sea level is what we're used to. In fact, we're so used to it that we forget we're actually feeling air pressure all the time! We are usually unaware of slight changes in air pressure, but rather quick changes can affect our bodies in more obvious ways. One example is the discomfort you feel in your ears when you ride in an elevator or airplane, or after a dive into a deep pool. At higher altitudes, air molecules are more spread out and there is less air pressure. Similarly, because water is heavier than air, the water pressure at the bottom of a deep pool is greater than air pressure when you return to the surface. If you have ever been in one of these situations, you may have noticed that you feel better after your ears pop.

\section{PAGE 2}

\begin{tabular}{|l|l|}
\hline Accurate repetition & Contrast \\
\hline So, why do our ears pop? & So, why do our ears pop? \\
This happens when the & The commonsense belief is \\
pressure inside our ears is & that this happens because \\
higher than the pressure & there is a large amount of \\
outside our ears. The middle & air pressure trapped inside \\
ear always contains some & our ears. A small part of \\
amount of air. Normally, the & the ear, the Eustachian \\
\hline
\end{tabular}

\begin{tabular}{|l|l|} 
Highlighted accurate repetition & Refutational \\
So, why do our ears pop? The & So, why do our ears pop? \\
general scientifically-accepted & Before learning why scientists \\
explanation is that this happens & think your ears pop, let's \\
when there is a difference & explore people's commonsense, \\
between the pressure inside and & yet inaccurate beliefs. People \\
outside our ears. The area inside & believe ears pop because there \\
our ears, the middle ear, always & is a large amount of air \\
\hline
\end{tabular}




\begin{tabular}{|c|c|c|c|}
\hline $\begin{array}{l}\text { Eustachian tube, which } \\
\text { connects the middle ear to } \\
\text { the throat - is closed. The } \\
\text { tube can, however, open to } \\
\text { let air into or out of the } \\
\text { middle ear. When you hold } \\
\text { your nose shut with your } \\
\text { fingers and blow into your } \\
\text { nose, you will hear your } \\
\text { ears pop and the pain should } \\
\text { go away. When you do this, } \\
\text { you open your Eustachian } \\
\text { tube. Yawning, sneezing, or } \\
\text { chewing gum can also open } \\
\text { up the Eustachian tubes. The } \\
\text { key premise is that opening } \\
\text { the tube allows the pressure } \\
\text { to balance out. After your } \\
\text { ears have popped, the air } \\
\text { pressure in your inner ear } \\
\text { becomes similar to the } \\
\text { atmospheric pressure. The } \\
\text { scientific explanation is } \\
\text { worthy of further detail. }\end{array}$ & $\begin{array}{l}\text { tube, needs to open to let } \\
\text { the air pressure out. When } \\
\text { you hold your nose shut } \\
\text { with your fingers and blow } \\
\text { into your nose, you will } \\
\text { hear your ears pop and the } \\
\text { pain should go away. The } \\
\text { idea is that, by blowing, air } \\
\text { is pushed out of your } \\
\text { Eustachian tube. Yawning, } \\
\text { sneezing, or chewing gum } \\
\text { can also open up the } \\
\text { Eustachian tubes. The key } \\
\text { premise of this explanation } \\
\text { is that the area in your ear } \\
\text { is under a large amount of } \\
\text { air pressure that needs to } \\
\text { be released. Once your } \\
\text { ears have popped, the } \\
\text { commonsense notion is that } \\
\text { there is no more air or air } \\
\text { pressure left inside the ear. } \\
\text { However, the scientific } \\
\text { explanation is a bit more } \\
\text { complex than this. } \\
\text { In fact, }\end{array}$ & $\begin{array}{l}\text { contains some amount of air. } \\
\text { Eustachian tubes - which } \\
\text { connect the middle ear to the } \\
\text { throat - can open to let air into } \\
\text { or out of the middle ear. When } \\
\text { you hold your nose shut with } \\
\text { your fingers and blow into your } \\
\text { nose, you will hear your ears pop } \\
\text { and the pain should go away. } \\
\text { When you do this, you open up } \\
\text { your Eustachian tubes. } \\
\text { Yawning, sneezing, or chewing } \\
\text { gum can also open up the } \\
\text { Eustachian tubes. These actions } \\
\text { contract several small muscles, } \\
\text { which regulate Eustachian tube } \\
\text { functioning. The key premise of } \\
\text { this explanation is that opening } \\
\text { the tube allows the pressure to } \\
\text { balance out. After your ears } \\
\text { have popped, the air pressure in } \\
\text { your middle ear becomes similar } \\
\text { to the atmospheric pressure. } \\
\text { This provides a nice overview of } \\
\text { the scientifically accepted } \\
\text { explanation. } \\
\text { To put it another way, scientific } \\
\text { experiments have shown }\end{array}$ & $\begin{array}{l}\text { pressure that has built up and } \\
\text { is trapped inside our ears. A } \\
\text { small part of the ear, the } \\
\text { Eustachian tube, needs to open } \\
\text { to let the air pressure out. } \\
\text { When you hold your nose shut } \\
\text { with your fingers and blow into } \\
\text { your nose, you will hear your } \\
\text { ears pop and the pain should go } \\
\text { away. The idea is that, by } \\
\text { blowing, air is pushed out of } \\
\text { your Eustachian tube. } \\
\text { Yawning, sneezing, or chewing } \\
\text { gum can also open up the } \\
\text { Eustachian tubes. The key } \\
\text { premise of this explanation is } \\
\text { that the area in your ear is } \\
\text { under a large amount of air } \\
\text { pressure that needs to be } \\
\text { released. Once your ears have } \\
\text { popped, the commonsense } \\
\text { notion is that there is no more } \\
\text { air or air pressure left inside } \\
\text { the ear. This belief, however, } \\
\text { contradicts the scientifically } \\
\text { accepted explanation. } \\
\text { In contrast, scientific } \\
\text { experiments have shown }\end{array}$ \\
\hline
\end{tabular}


there is always air pressure inside our ears, and always air pressure in the atmosphere. Our ears pop because our ears are trying to equalize the air pressure on either side of the Eustachian tubes. Air molecules always move from areas of high pressure to areas of low pressure. In this instance, air would move out until the air pressure in the inner ear is matched to that of the surrounding atmosphere. Thus, there is always some air pressure in all areas. When we dive to the bottom of a swimming pool, the air in our ears is under less pressure than the water around us. This causes water to be pushed into the inner ear. When we return to the surface, the pres sure inside our ears is greater than the outside air, and both water and some air molecules are pushed out. These are just a few everyday examples of the ways our bodies adjust to pressure changes.

\section{PAGE 3}

The same principles of air pressure and air movement are at work on a much larger scale for weather patterns. Atmospheric pressure varies widely on Earth, and these differences influence our daily weather. "High" pressure systems involve areas where the air pressure is higher than the pressure of the surrounding air. A "low" is where it's lower, comparatively. Scientists don't have a particular number that divides high from low pressure systems. Air pressure always exists in some amount in all weather systems. It's the relative differences that scientists find important to consider.

The winds and the weather that we experience result from interactions between pressure systems that have relatively different amounts of air pressure. Scientists use this relational perspective to explain the winds that move around the Earth's surface. Differences in air pressure measured across a given distance are called air pressure gradients. Pressure gradients cause air molecules to move from areas of high pressure to areas of low pressure, and we experience this movement as wind. The larger the gradient, the stronger the winds that are produced. When the air pressure gradient is less disparate, air does not move as quickly or with as much force. That is, if there is less to no air pressure gradient between two areas, air movement is much weaker and less noticeable. However, when the gradient is large, then strong winds will occur. Thus, not only is air pressure all around us, but its effects are all around us too. The effects of air pressure can be seen in many areas of everyday life ranging from effects on our bodies to effects on our planet and weather.

\begin{tabular}{|l|c|c|c|c|}
\hline & Accurate repetition & Contrast & Highlighted Accurate repetition & Refutational \\
\hline Word count & 878 & 885 & 904 & 904 \\
\hline Flesch Reading Ease & 66 & 66.6 & 63.6 & 65.4 \\
\hline Flesch-Kincaid Grade & 7.9 & 8.0 & 8.4 & 8.2 \\
\hline
\end{tabular}




\section{Appendix B}

Definitions and examples of accurate and inaccurate core concepts mentioned in student-generated "reasons for ears popping" essays

CORE CONCEPT 1: A student's response mentions that normally/typically, the air pressures inside and outside of ears are in a state of equilibrium, balance, or are similar/matched.

Accurate example: Your ears usually contain the same amount of air pressure as the atmospheric pressure in Chicago/at sea level.

Inaccurate example: The air pressure in our ears is always higher than the air pressure outside of our ears.

CORE CONCEPT 2: A student's response mentions that the person/ears move to an area of lower air pressure (outside of the ears) at higher altitudes.

Accurate example: If one were to ascend in an airplane, the air pressure outside of your ears would become lower at higher altitudes.

Inaccurate example: The higher you go up in an airplane, the higher the atmospheric pressure.

CORE CONCEPT 3: A student's response mentions that the inside of the ear now has relatively/comparatively higher air pressure inside. Accurate example: As you rise to higher altitudes, the air pressure in your ears becomes greater.

Inaccurate example: When you ascend in an airplane, your ears have relatively lower pressure.

CORE CONCEPT 4: A student's response mentions that the current situation involves a state of disequilibrium/imbalance/pressure difference between the two areas.

Accurate example: Ascension causes imbalanced pressure inside and outside of the ears.

Inaccurate example: When you ascend rapidly in an airplane and before your ears pop, the air pressure in your ears and outside in the atmosphere are balanced.

CORE CONCEPT 5: A student's response mentions that our bodies/ears seek equilibrium/balance or that the ears try to/want to balance/match the two areas.

Accurate example: Ears pop because a tube connects the inner ear to the throat opens to try to equalize the air pressure.

Inaccurate example: Air pressure does not attempt to establish equilibrium/balance.

CORE CONCEPT 6: A student's response mentions that air moves from areas of higher air pressure (inside ear) to areas of lower pressure (outside ear). 
Accurate example: Air is forced out of the middle ear, where the air pressure is higher, towards the outside of the ear, where the air pressure is lower.

Inaccurate example: Air moves from areas of lower to areas of higher air pressure.

CORE CONCEPT 7: A student's response mentions that equilibrium/balance is re-established or air pressure inside and outside has matched/become similar after our ears have popped.

Accurate example: Air moves out until the air pressure inside your ears and in the surrounding area outside of the ears are equal. Inaccurate example: Air moves out until the air pressure inside your ears is gone; i.e. there is no more air pressure in the ear. 
Table 1.

Mean correct answers on the multiple choice knowledge assessment pre and post reading as a function of learning condition, Experiments 1 and 2 (Standard deviations in parentheses)

\begin{tabular}{|c|c|c|c|c|c|c|}
\hline \multirow[b]{2}{*}{ Experiment 1} & \multicolumn{3}{|c|}{ Accurate Repetition Text } & \multicolumn{3}{|c|}{ Contrast Text } \\
\hline & PreTest & PostTest & Gain & PreTest & PostTest & Gain \\
\hline Fragmented & 2.45 & 4.64 & 2.19 & 2.15 & 4.77 & 2.62 \\
\hline Misconception & $(0.75)$ & $(1.56)$ & & $(0.83)$ & $(1.56)$ & \\
\hline Coherent & 2.00 & 4.32 & 2.32 & 1.87 & 4.74 & 2.87 \\
\hline \multirow[t]{2}{*}{ Misconception } & $(1.25)$ & $(2.09)$ & & $(1.09)$ & $(1.88)$ & \\
\hline & \multicolumn{3}{|c|}{ Highlighted Accurate Repetition Text } & \multicolumn{3}{|c|}{ Refutational Text } \\
\hline Experiment 2 & PreTest & PostTest & Gain & PreTest & PostTest & Gain \\
\hline Fragmented & 2.27 & 4.08 & 1.81 & 2.19 & 4.85 & 2.66 \\
\hline Misconception & $(0.96)$ & $(1.74)$ & & $(0.85)$ & $(2.07)$ & \\
\hline Coherent & 1.92 & 4.12 & 2.2 & 2.07 & 5.00 & 2.93 \\
\hline Misconception & (1.19) & $(1.59)$ & & $(1.05)$ & $(2.06)$ & \\
\hline
\end{tabular}


Table 2.

Adjusted mean proportion of accurate core concepts included in short answer essays responses as a function of learning condition, Experiments 1 and 2 (Standard deviations in parentheses).

$\begin{array}{ccc}\text { Experiment 1 } & \text { Repetition } & \text { Contrast } \\ \text { Fragmented } & 0.63 & 0.67 \\ \text { Misconception } & (0.30) & (0.33) \\ \text { Coherent } & 0.73 & 0.81 \\ \text { Misconception } & (0.29) & (0.24) \\ & & \\ \text { Experiment 2 } & \text { Highlighted } & \text { Refutation } \\ & \text { Repetition } & \\ \text { Fragmented } & 0.61 & 0.72 \\ \text { Misconception } & (0.31) & (0.30) \\ \text { Coherent } & 0.70 & 0.85 \\ \text { Misconception } & (0.24) & (0.20)\end{array}$


Refutational texts 60 